\title{
Training Communication Skills During COVID-19 Pandemic as a Part of Educational Process in Dental Medicine
}

\section{Yulia Bogdanova Peeva*}

Department of Social Medicine and Public Health, Faculty of Public Health, Medical University of Plovdiv, Bulgaria

Correspondence to: Yulia Bogdanova Peeva, Department of Social Medicine and Public Health, Faculty of Public Health, Medical University of Plovdiv, Bulgaria. Received date: August 17, 2021; Accepted date: August 27, 2021; Published date: September 4, 2021

Citation: Peeva YB (2021) Training Communication Skills During COVID-19 Pandemic as a Part of Educational Process in Dental Medicine. J Med Res Surg 2(4): pp. 1-5. doi: 10.52916/jmrs214053

Copyright: (C2021 Peeva YB. This is an open-access article distributed under the terms of the Creative Commons Attribution License, which permits unrestricted use, distribution and reproduction in any medium, provided the original author and source are credited.

\section{ABSTRACT}

Introduction: The training of dental students in communication skills has been faced with a new challenge related to the limitations of COVID 19. Obtaining informed consent and deciding on the need for treatment are part of the twoway dental-patient communication process. While training in Public Dental Health, the students learn the basic rules of patient-oriented communication, discussing models for successful conversation with the patient and the types of verbal and nonverbal communication. The main educational goal is to build dental professionals who can adequately accept the needs of patients, help to realize them and generate trust. The specific educational goal is to organize and discuss specific, evidence-based clinical skills for communicating with patients.

Materials and methods: A literature search has been performed and alternatives have been discussed with colleagues. The information search has been conducted using the Medline database (PubMed), Science Direct, and Web of Science.

Discussion: The development of the social element has been observed in the relationship dentist - patient. Against the background of growing commercialism in the provision of dental services, patients are feeling increasingly uncertain whether the treatment offered is the needed one. Therefore, the patient must be at the centre of modern dentistry where the primary role has the Medical University in educating ethical principles and building doctors dedicated to humanity.

Conclusion: The challenges in teaching students to communicate effectively with the patient are significant, especially in a global pandemic. The roots of philanthropy and empathy are laid back in time. They were described by the first teachers, physicians and philosophers in Medicine such as Hippocrates, Socrates, Plato, Aristotle and others. It is our responsibility just to repeat them.

\section{Keywords:}

Dentistry, Education, Comunication Skills, COVID-19.

\section{Introduction}

\section{The context for teaching communication skills in dentistry}

Prior to 1970, the clinical competence in the world included only three areas: medical and technical knowledge, physical examination and medical expertise.

The socio-clinical approach in solving patient's problem does not include training in communication skills. In fact, years ago the training and assessment of communication was not included in the curricula of the Medical Universities here. Communication too often is a long process. The respondent (the patient) is brought out of a state of passivity and makes a decision by thinking and actively participating in the prevention of personal health. One of the most serious values in the formation of health culture remains the building of health education from a very early age.

Over the past 30 years, the population of Bulgaria has been affected by various (political and financial) crises, with a negative impact on the quality of life and health. As a result, a large proportion of patients face the challenge of postponing their dental treatment due to the lack of funds. The same reason has affected the providers of dental care as well. It's known, that the OHCPs (Oral Health Care Providers) are accumulated in the big cities. The unequal distribution of OHIPs is the reason a large part of them to serve a small number of patients. Hence, there exists a problem for the need of distribution of dentists after their graduation. It's not a new talk that a limited access of health services exists. A lot of public health researchers' talk about geographical and financial limitation of healthcare access For example, high-altitude and remote settlements are not attractive to the OHCPs and people there suffer from a lack of primary care providers.

On the other hand, the aging population of the country implies an increased need for dental treatment, which puts the health care system at risk. Instead of primary or premorbid, the prophylaxis of oral diseases is carried out mainly as a tertiary. The process of redirecting the efforts of dental doctors and public health researchers must be in favour of the importance of primary prevention.

The main educational goal is to build dental professionals who can adequately accept the needs of patients, help to realize them and generate trust in them.

The specific educational goal is to organize and discuss specific, evidence-based skills for communicating with patients. 
Historically, the evolution of the problem has evolved from the Hippocratic Oath, which implements the age-old ethical principles of communication with the patient: "And whatsoever I shall see or hear in the course of my profession, as well as outside my profession in my intercourse with men, if it be what should not be discussed outside, I will never divulge, holding such things to be holy secrets. ... I will keep my life pure and sacred, as well as my art". The idea of communication based on ethical principles goes through the "Socrates method" to search for truth. Socrates convincingly claims that it was not flashes or external learning that would reveal the truth to us, but systematic, unperturbed reflection. Socratic method is also known as a form of cooperative argumentative dialogue between individuals [1,2].

The "Dialogues" written by Plato are used to teach various disciplines, including philosophy, logic, ethics, rhetoric, and mathematics. He developed in them a new philosophical doctrine for the substantial existence of ideas. The connection with the teaching of communication skills in dental medicine is expressed in the formation of ideas based on active search, rather than offering ready-made answers.

The training of communicative skills of dentists is carried out through the ethical principles of the Declaration of Helsinki, the European Charter of Patients' Rights and the Code of Professional Ethics of Bulgarian dentists and other internationally recognized documents that present the principles of autonomy, beneficence, non-maleficence and justice in medical ethics [3-5].

A modern analysis of the relationships in dental practice includes not the mentioned, but rather seven ethical principles - non-maleficence, beneficence, health maximisation, efficiency, respect for autonomy, justice, proportionality. Easy-to-use "tools" applying ethics to public health are presented. There is an emphasis on the practical application of certain theoretical formulations in practice. The authors have developed and practiced an approach to how ethics can be taught even in crowded curricula. In this way, if programme curricula do not allow more time for ethics, students of public health can at least be sensitized to ethics and ethical argumentation [5].

The importance of communication skills as a part of social interaction is also found in some Bulgarian proverbs: "On clothes you will be welcome - on the mind you will be sent", "If you sow winds you will reap storms, If you sow thought, you will reap action"...

And Arabic proverbs: "If you sow character, you will reap destiny".

\section{Material and Methods}

A literature search has been performed and alternatives have been discussed with colleagues. The information search has been conducted using the Medline database (PubMed), Science Direct, and Web of Science.

\section{Discussion}

\section{Definition (working definition)}

A process of social interaction, carried out through oneway dissemination of information and mutual exchange of messages. As a result, a certain degree of awareness and mutual understanding between the participants is achieved. It is also of interest to use singular and plural terms: the singular communication involves the exchange of messages.
Communication is between people, communication is the connection and emotion between these people. This is the kind of communication that is present every day in people's lives - the social element. The use of the plural refers to the technological aspect of the process - the systems through which the message is transmitted - devices such as telephone, TV, smart device.

\section{Characteristics of communication in dentistry:}

- Universal;

- Required;

- $\quad$ Symbolic (symbols, words, numbers, gestures);

- Subjective (our own experience, knowledge, skills);

- Learning, building;

- It is related to the use of technical means;

- Requires reciprocity;

- Type of culture;

- $\quad$ Striving for self-awareness; self-assessment; comparison;

- Invisible (hidden meaning of words, symbols) [6,7].

Health needs and their satisfaction are the main reason for the establishment of specific communication in Medicine, going through several stages (Figure 1). A health problem of a different nature-physical pain, emotional discomfort, situation, condition or any other deviation from the health norm, which is traditionally defined as "pain-related complaint" is the first step in medical communication and the cause of the patient to visit a dentist practice [8-10].

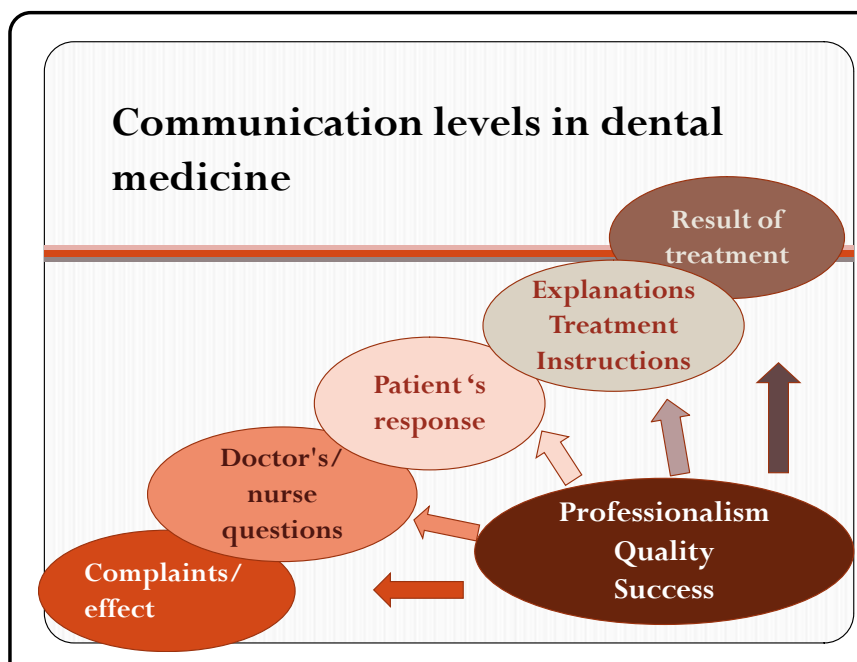

Figure 1: Communication levels in dental medicine.

\section{The new givens}

Due to the COVID-19 pandemic, the programme for clinical communication skills of the undergraduate training in dental medicine at the Medical University - Plovdiv has been transformed into an online format. The challenges facing this endeavor are related and depend on the social interaction between at least two people. The computer limits this interaction and is a kind of wall, especially when it comes to teaching 10, 20 or 30 people. The transmission, discussion and reception of information become a one-way rather than a twoway process. Control over the active presence of students is impossible or at least difficult [10-13].

Various models that could increase the communication satisfaction of both the patient and the dentist have been presented in Figure 2. The presence and limitations 
accompanying COVID-19 determine the importance of 1. Aristotle's communicative model communication worldwide.

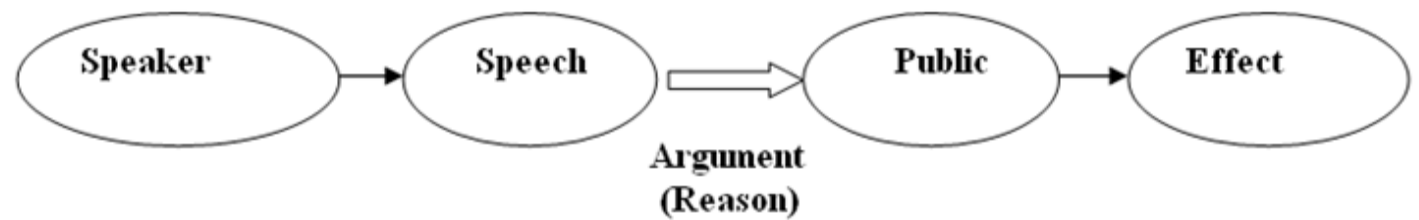

Figure 2: Presentation of the Aristotle's communicative model, applicable in dental practice.

\section{Laswell model, 5 "W" model}

- Who says?

- What does he say?

- What tool does he use?

- Who is he talking to?

- What he achieves?

\section{Shannon and Weber model.}

What the different models of communication have in common is the recognition of three conceptual parts.

The first focuses on defining the area of discussion, including the basic prerequisites, the types of communication skills and the goals that can be achieved by improving communication skills in the field of medicine. The second part explores the "first principles" of effective communication. The third part discusses an approach to identifying and organizing specific, evidencebased skills for communicating with patients.

\section{Del Heims model - SPEAKING:}

$\mathrm{S}$ - Setting (setting and scene)

$P$ - Participants

E - Ends

A - Act sequence (course of action, ie form and content of the message)

K - Key

I - Instrumentalities (instruments, ie channels for conveying the message and form of speech: oral, written, dialect, standard language, etc.)

$\mathrm{N}$ - Norms (speech norms)

G - Genres (genres of speech)

Certain contradictory trend from the practice in dentistpatients communications during COVID-19 pandemic:

- Young people often ignore or hide symptoms of virus infection leaving the dentist to assess the real state of the patient using thermometer against his forehead or pulseoxymeter or by other means;

- Elderly, especially in remote villages, prefer to remain isolated, thus minimizing the threat of their lives at the expense of the risks arising from complete lack of dental care;

- The above communications may continue to proceed on a one-way band, since the dentist must wear face shield, mask, gloves, and special clothing while the patient looks like in a state of emergency: no PCR test, no vaccination or other medical proofs certifying his status in respect of the virus;

- On the other side of the safety scale is the border control, the shopkeepers and even the restaurants at certain conditions;
- The training of undergraduates in dental medicine is by necessity (regulations!) and regrettably far from the real practice when the training process is...online.

Types of communications

- Verbal

1. Lips - Interpersonal Communications (IPC), Mass and Organizational

2. Written - IPC and Organizational

- Nonverbal

1. Gestures, facial expressions, position in space

On the other hand, communication skills can be considered as:

- Content skills

- Procedural skills

- Perceptual skills (perception skills)

- Content skills: What doctors say: for example, the content of the questions they ask and the answers they receive; the information, the list of differential diagnoses, the medical knowledge base on which they rely.

- Procedural skills: The way doctors talk to patients, for example: how they put questions, how well they listen, how they explain and plan with the patient, how they structure the interaction and how they illustrate this structure for the patient - through signs or guidance, how they build relationships $[14,15]$.

- Perceptual skills (perception skills): Thoughts and feelings, such as awareness of own decision-making processes and other thought processes; awareness of own attitudes and emotions during the interview, attitude towards the patient - prejudices, noise or discomfort that distract doctor from the attention to the patient.

- Content and procedural skills: Are more interpersonal in nature but the perception skills are more personal. The three types of skills are inextricably linked - each affects the others. Until recently, procedural communication skills were not given the least attention in medical education. Currently, procedural skills tend to be the main focus of communication skills training programs, while content and perceptual skills receive much less attention.

The idea behind the Johari's Window or the Personality Window is to classify human behavior into a matrix formed at the basis of what we know and do not know about ourselves and others about us (Figure 3):

It is a square divided into four parts. Each of them represents information about a person. Johari's Window is an image of a person's personality.

- Public figure - Man has his part, which is public 


\begin{tabular}{|l|c|l|}
\hline \multirow{2}{*}{$\begin{array}{l}\text { Known } \\
\text { for others }\end{array}$} & $\begin{array}{c}\text { Known for } \\
\text { me }\end{array}$ & Unknown for me \\
\cline { 2 - 3 } & Arena & Blind spot \\
\hline $\begin{array}{l}\text { Unknown } \\
\text { for others }\end{array}$ & Facade & Unknown \\
\hline
\end{tabular}

Figure 3: Self-knowledge and evaluation of others about the personality through "Johari's Window".

- $\quad$ Private person - A person knows something about himself that he does not reveal to other people

- Blind spot - Behavioral factor

- Unconscious, unknown area - Unconscious, subconscious and unconscious

A person increases his self-knowledge when he talks about himself and listens to the opinion of others about him.

The development of an already successful practice in which there are many patients leads to problems of different nature and severity for OHCPs:

- lack of personal time and time for treatment;

- does not speak;

- does not listen;

- lack of empathy;

- commercial approach to the patient;

- lack of resources: human, time, financial;

- terminological dictionary.

In the last two years, the problems associated with communication in dental practice have been brutally displaced by the fact of whether to communicate at all, whether to treat at all. The ethical principles and the different casuistry of the clinical problems put before many dentists the need to close their practices. The BDA reported data on deceased colleagues due to the pandemic.

Of interest are the notions that dentists, who are often confronted with various infectious diseases, are better prepared and hence, their assessment of infection control in dental practice is more clear and accurate.

Improving communication in dentistry allows clinicians to have ample time to communicate with patients, learn, enhance and maintain these new skills. There are fears that the health care system, in its efforts to be more efficient, is keeping us dangerously close to the edge when it comes to time [17-19].

The solution of the problems for achieving the Good Medical Practice is related to the development of professional integrity/ competence; communication skills; ethical behavior; dignified treatment of patients; ability to work in team.

On the other hand, communication skills are part of the specific skills of each doctor of dental medicine (Figure 4). Different models of the patient-dentist relationship have been proposed, as each of them contributes to achieving mutual understanding, satisfying the patient's needs and increasing the quality of care:

1. Model of consent (Parsons 1951);

2. Model of interdependence (Shaz and Hollander, 1956);

3. Model of conflict (Friedson, 1970);

4. Model of Conflict and Control (Stewart and Rother, 1989);

5. Model of psychological care (Humphreys and Lynch) informational and emotional needs.

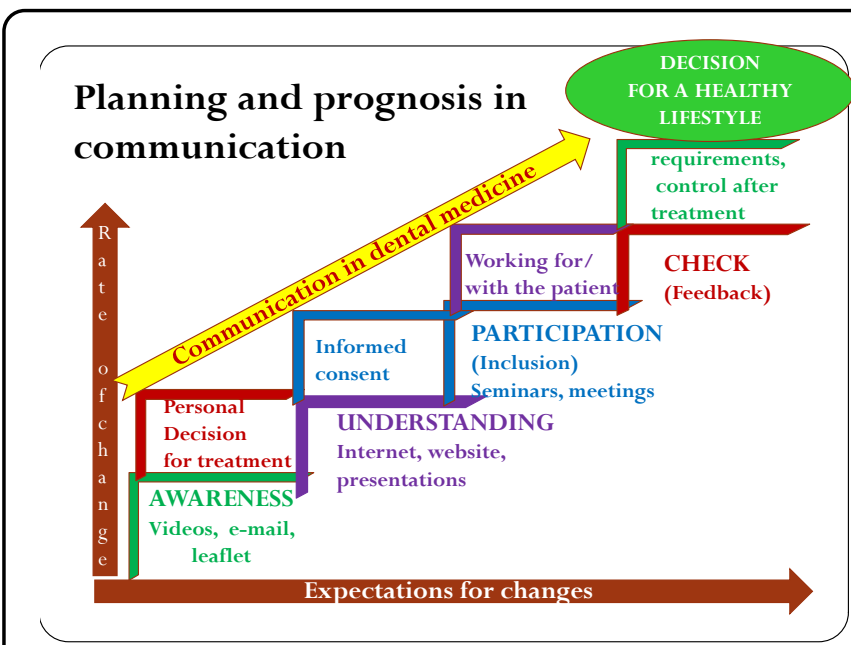

Figure 4: From "Good morning" to decision for a healthy life style because of good communication skills.

\section{Conclusion}

The creation, organization and development of communication skills leads to:

1. Encouraging cooperation and partnership - focusing on patient-centered care;

2. Increasing the accuracy, efficiency, support;

3. Increasing the satisfaction of the patient and the doctor;

4. Improving health results.

5. If the doctor speaks to the patient calmly, with understanding and attention, no doubt, the patient will feel better, no matter what his suffering

6. Communication skills are part of the skills that every doctor must have to implement quality, long-term and successful treatment.

7. The advantages of DDM that have communication skills are significant.

DDM will have a clearer idea of the patient's problems; will know what to expect from him as a behavior and attitude of the dentist's chair; will be able to engage the patient to follow his recommendations and advice; will leave the patient more satisfied with the treatment. The trust and authority of the doctor is not built only on excellent professional knowledge and skills. It is necessary for the patient to feel the whole radiance of the doctor's personality, this includes empathy, personal care, attention, time, support, understanding and respect for the feelings and emotions of the patient.

8. In the catch of COVID 19, one of the few positive things that has happened is the rapid development, impetus and use of technology so as not to interrupt the educational process and the rapid implementation of telehealth on community.

9. Simplified communication and a live connection with the patient are preferred. 


\section{Funding}

This research received no external funding.

\section{Conflicts of Interest}

The author declares no conflict of interest.

\section{References}

1. Marks J (2021) Medical Definition of Hippocratic Oath. MedicineNet. https://www.medicinenet.com/hippocratic oath/definition.html

2. Vlastos G ed., The Philosophy of Socrates, Notre Dame: University of Notre Dame Press, 1971.

3. Modi J, Anshu, Chhatwal J, et al. (2016) Teaching and Assessing Communication Skills in Medical Undergraduate Training. Indian Pediatr 53(6): pp. 497-504.

4. Frankel R. Sherman $H$ (2015) The secret of the care of the patient is in knowing and applying the evidence about effective clinical communication. Oral Dis 21(8): pp. 919-926.

5. Schröder-Bäck P, Duncan P, Sherlaw W, et al. (2014) Teaching seven principles for public health ethics: towards a curriculum for a short course on ethics in public health programmes. BMC Medical Ethics 15 (1): pp. 1-10.

6. Hannah A, Lim B, Ayers K (2009) Emotional intelligence and clinical interview performance of dental students. J Dent Educ 73(9): pp. 1107-1117.

7. Al-Hadi N, Chegini S, Klontzas M, et al. (2019) Patient expectations and satisfaction following orthognathic surgery. Int J Oral Maxillofac Surg 48(2): pp. 211-216.

8. Salgado H, Castro-Vale I (2020) Clinical Communication Skills Training in Dental Medical Education: The COVID-19 Pandemic Challenge. Healthcare 8(4): pp. 429.

9. Kadanakuppe S (2015) Effective Communication and Empathy Skills in Dentistry for Better Dentist-Patient Relationships. J Dent
Probl Solut 2(3): pp. 58-59.

10. Neville $P$, van der Zande M. Dentistry, e-health and digitalisation: A critical narrative review of the dental literature on digital technologies with insights from health and technology studies. Community Den. Health 37(1): 51-58.

11. Mascitti M, Campisi G (2020) Dental Public Health Landscape: Challenges, Technological Innovation and Opportunities in the 21st Century and COVID-19 Pandemic. Res. Public Health 17(10): pp. 3636.

12. Eckles RE, Meslin EM, Gaffney M, et al. (2005) Medical ethics education: where are we? Where should we be going? A review. Acad Med 80(12): pp. 1143-1152.

13. Compton S, Sarraf-Yazdi S, Rustandy F, et al. (2020) Medical students' preference for returning to the clinical setting during the COVID-19 pandemic. Med. Educ 54(10): pp. 943-950.

14. Tempski P, Arantes-Costa FM, Kobayasi R, et al. (2021) Medical students' perceptions and motivations during the COVID-19 pandemic. PLoS One 16(3): pp. e0248627.

15. Lincango-Naranjo $E$, Espinoza-Suarez $N$, Solis-Pazmino $P$, et al. (2021) Paradigms about the COVID-19 pandemic: knowledge, attitudes and practices from medical students. BMC Med Educ 21(1): pp.128.

16. World Health Organization. Coronavirus disease 2019 (COVID-19) Situation Report-83. https://apps.who.int/iris/ handle/10665/331781

17. Guan WJ, Ni ZY, Hu Y, et al. (2019) Clinical Characteristics of Coronavirus Disease 2019 in China. N Engl J Med 382(4):17081720.

18. Gibbs T (2020) The Covid-19 pandemic: Provoking thought and encouraging change. Med Teach 42(7): pp. 738-740.

19. Di Giacomo P, Di Paolo C. (2021) Covid-19 and dental distance-based education: students' perceptions in an Italian University. BMC Med Educ 21(1): pp. 414. 